\title{
Oral Findings and Dental Care in a Patient with Myelomeningocele: Case Report of a 3-Year-Old Child
}

\author{
Alexandra Mussolino de QUEIROZ \\ Regina Aparecida Segatto SAIANI \\ Cristhiane Ristum Bagatin ROSSI \\ Jaciara Miranda GOMES-SILVA \\ Paulo NELSON-FILHO
}

\author{
Department of Pediatric Clinic, Preventive and Community Dentistry, \\ Ribeirão Preto Dental School, University of São Paulo, Ribeirão Preto, SP, Brazil
}

\begin{abstract}
Myelomeningocele (MMC) is a congenital malformation of the neural tube that occurs in the first weeks of pregnancy. This malformation refers to the caudal non-closure of the neural tube and neural tissue exposure, which lead to neurological problems, such as hydrocephalus, motor disability, genitourinary tract and skeletal abnormalities and mental retardation. Patients with MMC have an acknowledged predisposition to latex allergy and are usually at a high caries risk and activity due to poor oral hygiene, fermentable carbon hydrate-rich diet and prolonged use of sugar-containing medications. This paper addresses the common oral findings in pediatric patients with MMC, discusses the strategies and precautions to deal with these individuals and reports the dental care to a young child diagnosed with this condition.
\end{abstract}

Key Words: myelomeningocele, neural tube, spina bifida, dental treatment.

\section{INTRODUCTION}

Neural tube defects (NTD) are malformations that occur within the early phases of fetal development, involving the primary structure that will originate the brain and the spinal cord (1). Traditionally, NTD may be classified in 2 groups: deficiencies affecting the skull structure (anencephaly and encephalocele) and deficiencies involving the medullar structure (spina bifida). Skull malformations have greater clinical evidence and are often incompatible with life (2).

Spina bifida (SB) is a congenital malformation of the spinal cord with simultaneous vertebral alterations, due to incomplete closure of the neural tube. It has 2 clinical forms, namely open spina bifida (OpSB) and occult spina bifida (OcSB). While in the open variety the defect is clearly identified at birth, in the occult type the malformation is not apparent and has no clinical significance at birth (3).

OcSB is actually the benign form of OpSB, pro- ducing an opening in one or more vertebrae, without apparent medullar damage (3). OcSB patients are often asymptomatic and unaware of this alteration (1). A small undulation of hair on the skin that covers the spine may eventually be noticed (2). OpSB is more severe and is characterized by the presence of a cyst on the dorsal region (3). It is one of the most frequent central nervous system malformations, occurring in 1:800 liveborns (4). There are 2 types of OpSB, depending on the moment of occurrence, namely: meningocele, if the onset period is after the 4th week of pregnancy, and myelomeningocele (MMC), if the onset period is before the 4th week of pregnancy (3). Meningocele is a benign variant of OpSB, involving protrusion of the meninges and spinal liquid, which are contained in a cyst. It is covered by normal skin and presents no nerve elements in the cyst. This form of OpSB does not result in neurological damage. MMC is the most severe and frequent form of OpSB. It presents a cul-de-sac projection that contains part of the medulla, the meninges and spinal liquid protruding from a spinal 
opening. In some cases the projection is covered by skin, but tissue and nerve exposure may also be present (1). The cyst may burst at childbirth or soon after it. In such cases, the medulla and/or the nerve roots are covered by thin membranes and exposed to external environment (3). In $80 \%$ of the cases, the cyst occurs in the lumbar region. Other possible sites in a decreasing order of frequency are the cervical, sacral and thoracic regions. It may also extend along the entire length of the spine and be associated with variable degrees of myelodysplasia (3). Patients with MMC may present muscular weakness or paralysis below the affected segment and sphincter incontinency. Hydrocephalus is present in $70-90 \%$ of newborns with MMC and, though it may occur in the absence of SB, both disoreders are commonly associated (1).

The prognosis for SB patients depends on the number and severity of the malformations and is worse for those presenting complete paralysis, hydrocephalus and other congenital deficiencies. Children with SB may reach adult age if properly treated (1). The sensory and motor alterations vary according with the severity of the damage and the degree of medullar involvement. Wheelchair locomotion is required for $90 \%$ of the patients with thoracic-lumbar lesions, $45 \%$ of those with lumbar lesions and $17 \%$ with sacral lesions. Unassisted walking is possible to $57 \%$ patients with sacral lesions, $7 \%$ with lumbar lesions and impossible to those with thoracic-lumbar lesions (5). Obesity may be present in $40 \%$ of the cases (6).

NTD have a multifactorial etiology, with overlapping between genetic predisposition and environmental conditions (7). Genetic predisposition occurs by a recessive autosomal inheritance pattern, with high recurrence risk. Women that gave birth to a child with NTD present a tenfold greater chance of giving birth to another child with NTD than the general population. Chromosomal abnormalities occur at lesser rates and the other possible causes include: exposure to teratogenic agents, maternal environmental contamination, gestational diabetes, hyperthermia and obesity $(8,9)$.

Regarding oral health, children with NTD are at high caries risk due to a deficient diet, poor oral hygiene and prolonged use of sugar-containing oral medicines. MMC patients need assistance to do most of everyday tasks. The physical disabilities, limitations and medical problems of these patients are so demanding that, sometimes, oral health care is excusably not regarded as a priority. Dental care of special needs patients is usually complicated due to a combination of factors that might include uncontrolled involuntary body movements, lack of motor ability, intellectual deficit and difficult to open the mouth or inability to maintain a sufficient interincisal space to permit adequate hygiene or treatment (10).

During dental treatment, additional care should be taken because MMC patients have acknowledged predisposition to latex allergy, with prevalence ranging from 28 to $67 \%$ (10). Based on the facts that defects in the prenatal development of the brainstem can result in cranial nerve deficiencies and that the development of tooth germs is dependent on the nerve trigeminus, Linderstrom et al. (11) have investigated the hypothesis that brainstem anomalies would lead to an increased prevalence of tooth agenesis and malformation.

The hypothesis was rejected because the authors could not demonstrate that patients with brainstem anomalies have a higher risk of developing tooth agenesis as a result of cranial nerve deficiencies. In a review article Kjaer (12) discussed the association between the peripheral nerves and the development of the dentition. Prenatal innervation of the dentition is presented. Agenesis and tooth malformation occur in constant patterns within the dental arch fields that share the same innervation. The findings demonstrate that in postnatal diagnosis of the cranium and the teeth, traces of prenatal aberrations can be found that are important for neurofacial growth.

This paper addresses the common oral findings in pediatric patients with MMC, discusses the strategies and precautions to deal with them and reports the dental care to a young child diagnosed with this condition.

\section{CASE REPORT}

A3-year-old Caucasian female child weighing 12 $\mathrm{kg}$ and having a diagnosis of MMC and hydrocephalus was referred for general dental treatment at the Center for Formation of Human Resources Specialized in Dental Care to Special Needs Patients of Ribeirão Preto Dental School, University of São Paulo, Brazil.

During the clinical interview, the mother reported that the child was born by cesarean delivery weighing $4,071 \mathrm{~kg}$. Twenty-four hours after birth, the child was operated for placement of an intracranial valve and removal of a cystic lesion. NTD had not been detected in the prenatal ultrasound images and the child was diagnosed as having MMC only after birth. The mother had gestational diabetes and review of medical history 
indicated folic acid deficiency in the mother's organism as a probable cause of child's MMC.

The patient was under use of anxiolytic (Frisium ${ }^{\circledR}$; tablets) and anticonvulsive (Tegretol ${ }^{\mathbb{}}$ ) drugs and attended physical therapy sessions twice a week and speech therapy once a week at the Assistance Association to the Defective Child (AACD in the Portuguese acronym). In spite of being unable to walk or talk, the child communicated satisfactorily with her parents. The child was neither breast nor bottle fed, drank milk from a glass, had difficult on mastication and did not like sweetened foods.

Intraoral clinical examination revealed active white spot lesions in the anterior primary teeth, cavited caries lesions in all primary teeth, gingival inflammation and anterior open bite (Fig. 1). Agenesis of the primary mandibular right lateral incisor and its permanent successor was confirmed radiographically. The permanent maxillary lateral incisors were conoid teeth (Fig. 2).

Two initial sessions were undertaken for child's psychological conditioning and familiarization with the dental staff, equipment and procedures. Thereafter, a comprehensive individual-targeted program was settled based on the patient's caries risk and activity status. The strategies included instruction on caries prevention, diet counseling to reduce the intake of sucrose-rich foods and training of the mother on at-home oral hygiene (toothbrushing and flossing). Much time and effort were invested to highlight that oral homecare should be supportive to the professional care provided at the clinics and that family commitment and partnership approach were

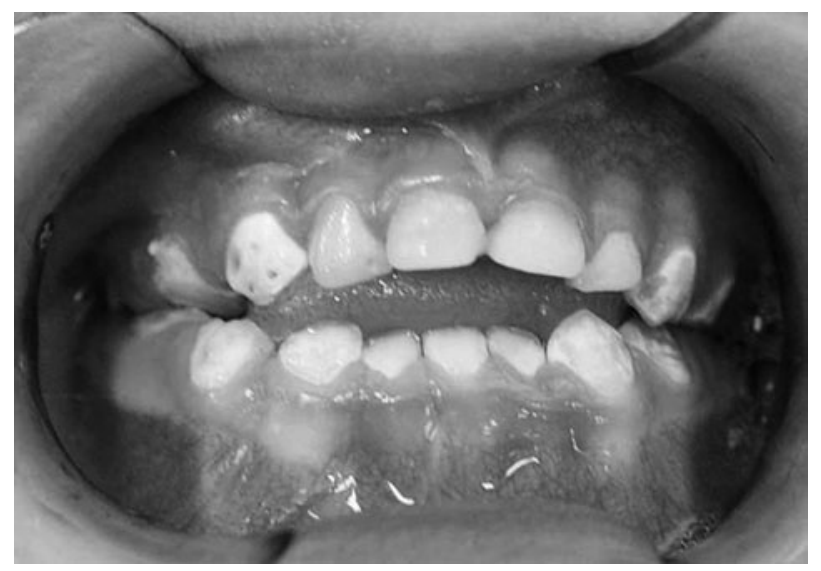

Figure 1. Preoperative clinical view showing active white spot lesions in the anterior teeth, multiple cavited caries lesions, gingivitis, anterior open bite and missing primary mandibular right lateral incisor. essential for maintaining an adequate oral health status.

Because of the patient's high caries risk and activity, 4 sessions were scheduled consisting of pumice/ rubber cup prophylaxis and topical application of $0.12 \%$ chlorhexidine gluconate solution (Noplak; Laboratório Daudt Oliveira Ltda., Rio de Janeiro, RJ, Brazil) and $1.23 \%$ acidulated phosphate fluoride gel (Sultan Topex; DFL Ind. e Com. Ltda., Petrópolis, RJ, Brazil). After gross carious tissue removal, all cavited teeth were filled with conventional glass ionomer cement (Vidrion R; SSWhite, Rio de Janeiro, RJ, Brazil). All interventions were performed under local anesthesia. Neither conscious sedation nor professional physical restraint was necessary. The child was accommodated on her father's lap using pillows, foam pads and rolls, when necessary, in such a way to make her comfortable and provide a good working position to the dentist, resulting in shorter and less fatiguing clinical sessions. A latex-safe protocol was adopted in all clinical sessions.

An extensive rehabilitating treatment was planned comprising endodontic treatment and placement of stainless steel crowns, amalgam and composite restorations (Fig. 3). The dental treatment was completed within around 1 year with weekly clinical sessions. In the 5-year followup visit, child presented controlled caries risk and adequate restorations. Clinical sessions have been scheduled on a 3-month basis for examination, professional prophylaxis, topical fluoride application and reinforcement of oral hygiene instructions. The family has been very cooperative.

Ethics Committee approval (\#2005.1.422.58.0) and

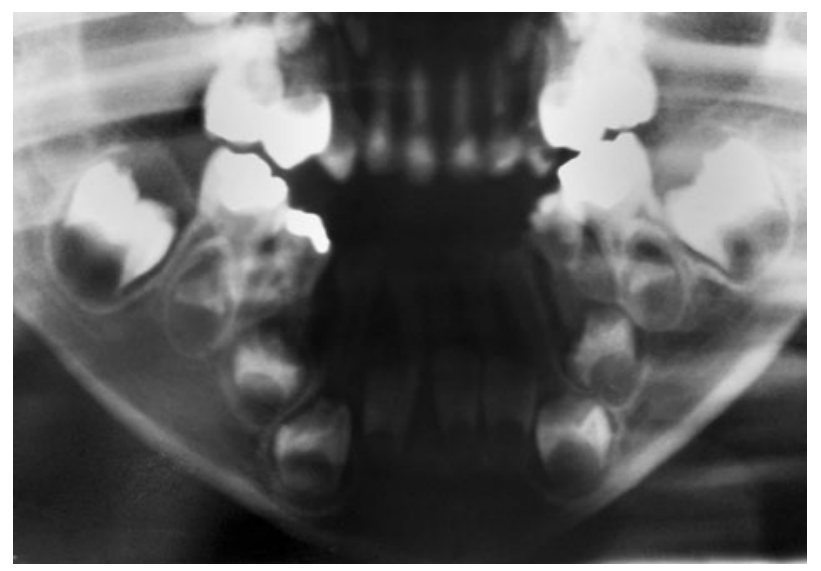

Figure 2. Preoperative panoramic radiograph showing agenesis of the primary mandibular right lateral incisor and its permanent successor, and conoid permanent maxillary lateral incisors. 
parental written informed consent were obtained for case report and disclosure of child's uncovered photographs.

\section{DISCUSSION}

Caries disease is frequently an additional hindrance in specific pediatric populations. Children with severe NTD, such as MMC, are prime candidates for childhood dental caries because of multiple factors. Their neurological impairment can make dental care challenging, which is further complicated by a frequently poor oral hygiene and nutritional intake. Many of these children tend to be overweight, which can be due to frequent snacking and impaired mobility due to the nature of their disability $(10,13)$. Caloric intake by these children often exceeds energy expended and is coupled with a lack of stimulation from physical activities. Parents/caregivers may use food to show affection or as a reward. A low-consistence diet rich in fermentable carbon hydrates allied to limited self-cleaning oral movements is also contributory. Plus, individuals on long-term medications for health problems, like MMC, are usually more susceptible to caries because of the high sucrose content of most medications. Without effective oral hygiene, these conditions create a perfect environment for cariogenic bacteria. These children often are scheduled for extensive dental rehabilitation $(10,14)$. All these characteristics were observed in the child of the present case report.

MMC can interfere with activities of daily living and often children with this disability need assistance with eating, clothing and toileting from parents/caregivers. In the midst of all these needs, diligent oral hygiene may understandably be considered less important and thus be overlooked. However, dental health in children with special needs is as essential as immunizations, regular physical examinations and attention to injury prevention (10). In the present case, the mother attributed the child's poor oral status to the overloading care imposed by the MMC. However, she became very cooperative after receiving instructions on at-home oral care and being told on the importance and benefits that a good health condition could bring to her daughter.

Statistical data on how many children with MMC actually experience dental caries are difficult to find. These children are recognizably at greater risk for caries and periodontal disease than the general population. In addition, allergy to latex is an important concern.

Latex sensitivity is a life-threatening allergy and is common in pediatric patients with NTD. There are 3 main types of latex sensitivity reactions, ranging from milder to more severe: contact dermatitis, allergic contact dermatitis, and immediate hypersensitivity or immune globulin E (IgE)-mediated reaction, caused by the natural latex proteins found in rubber, which can result in anaphylaxis $(15,16)$. Recurrent exposure to latex contributes to antibody formation and triggering of immediate hypersensitivity. This condition has a strong implication for dentists treating SB patients because materials either containing or made from latex, such as gloves, rubber dam and radiographic films, are widely used in the clinical dental practice (17) and might unchain allergic responses and even anaphylactic reactions (18). A latex-free environment must be adopted for treatment of these patients (19).

Given the number of sensitized individuals and assuming that this number will rise with increasing exposure to latex, an efficient latex protocol should be implemented in dental offices. Patients should be screened by taking a detailed medical history, and precautions should be used when treating individuals at high risk for developing latex allergies. These precautions should be continued until an allergist has verified the patient's allergic status, and
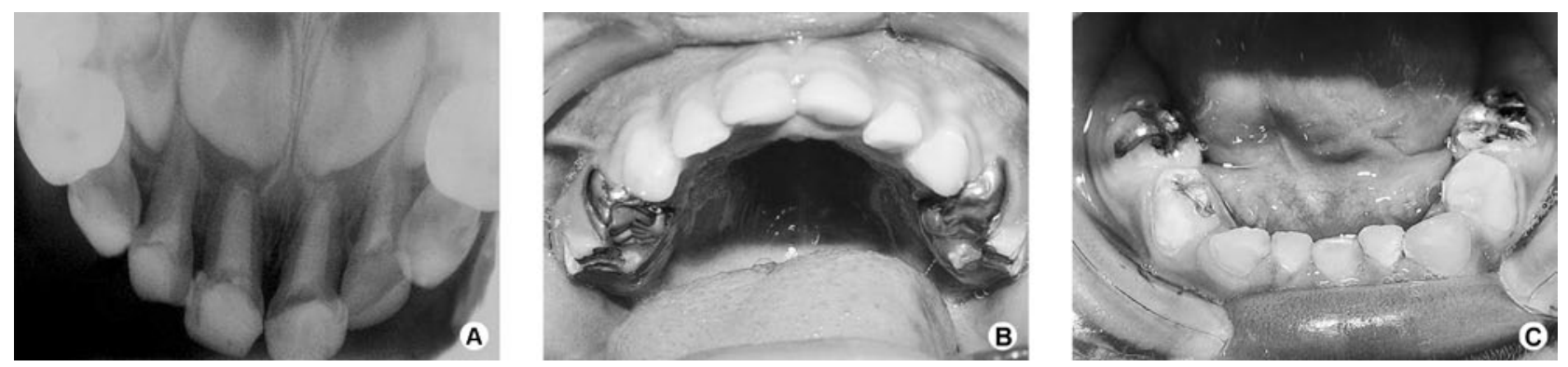

Figure 3. Rehabilitation comprising endodontic treatment and placement of stainless steel crowns, amalgam and composite restorations. 
ruled out latex allergy as a concern (20).

The case presented herein is one more example that children with MMC are high-caries-risk patients and should receive early dental care. In-office dental visits should start even before eruption of the first teeth and the parents/caregivers should be well instructed and trained on at-home dental care. In this particular case, the parents had never been alerted on the importance of taking the child to a preventive dental consultation at a very early age, which is a common finding. Toothbrushing is usually challenged by several conditions including the patients' inability to rinse/spit and keep their mouth open, voluntary/involuntary movements and vomiting reflexes during brushing. Parents/caregivers should be enlightened and trained on the use of auxiliary resources should as mouth openers and physical restraint strips, if necessary. The use of electric, adapted or custom-made toothbrushes should also be stimulated whenever possible. In more severe cases, prescription of antimicrobial agents and scheduling of more frequent professional care sessions are essential approaches in addition to home-based oral hygiene measures. Special care dentists have gained an increasingly recognized importance as members of multidisciplinary teams assisting special needs patients and should take responsibility, as health professionals, not only to render in-office preventive programs, but also to act as spreaders of information on oral health care in their communities. This might be an important contribution to improve the life quality of these patients, as oral health education aims to disseminate knowledge and develop skills and attitudes consistent with healthy oral conditions. Special care dentists also have an important supportive role for parents/caregivers of disabled patients to help them making oral homecare less challenging.

\section{RESUMO}

Mielomeningocele (MMC) representa uma malformação congênita do tubo neural que acontece nas primeiras semanas de gestação. Esta malformação refere-se ao não fechamento da coluna vertebral expondo a medula espinhal, que levará a problemas neurológicos, como hidrocefalia, dificuldades motoras, anomalias esqueléticas e do trato genito-urinário, além de retardo mental. Pacientes com MMC apresentam uma reconhecida predisposição à alergia ao latex e geralmente apresentam um alto risco e atividade de cárie dental decorrente de uma higiene oral deficiente, de uma dieta rica em carboidratos e do uso prolongado de medicamentos contendo açúcares. Este trabalho discorre sobre os achados bucais em crianças com MMC, discute as estratégias e precauções no manejo destes pacientes e descreve o tratamento odontológico de uma criança diagnosticada com esta condição.

\section{REFERENCES}

1. Hasenau SM, Covington C. Neural tube defects. MCN Am J Matern Child Nurs 2002;27:87-91.

2. Frey L, Hauser WA. Epidemiology of neural tube defects. Epilepsia 2003;44:4-13.

3. Farley J, Dunleavy MJ. Myleodysplasia in pediatric nursing: caring for children, second ed. Stamford, Conn: Appleton and Lange; 1999:659.

4. Ozveren MF, Erol FS, Topsacal C, Tiftikci MT, Akdemir I. The significance of the percentage of the defect size in spina bifida cystica in determination of the surgical technique. Childs Nerv Syst 2002;18:614-620.

5. Hisaba WI, Morow AF, Cavalheiro S. Open spina bifida: antenatal ultrasound findings and uterine contractions as predictors of the neonatal neuromotor outcome. Rev Bras Ginecol Obstet 2003;25:425-443.

6. Fiore P, Picco P, Castagnola E, Palmieri A, Levato L, Gremmo M, et al.. Nutritional survey of children and adolescents with myelomeningocele (MMC): overweight associated with reduced energy intake. Eur J Pediatr Surg 1998;8:34-36.

7. Czeizel AE. Folic acid in the prevention of neural tube defects. J Pediatr Gastroenterol Nutr 1995;20:4-16.

8. Shaw GM, Velie EM, Shaffer D. Risk of neural tube defect affected pregnancies among obese women. J Am Med Assoc 1996;275:1093-1096.

9. Perlow JH. Education about folic acid: the ob-gien"s role in preventing neural tube defects. Contemp Ob Gyn 1999;44:39-53.

10. Hudson ME. Dental surgery in pediatric patients with spina bifida and latex allergy. AORN J 2001;74:57-63,65-66,69-70 passi; quiz 73-8.

11. Linderstrom A, Samuelsson L, Huggare J. Is tooth agenesis related to brainstem anomalies in myelomeningocele patients with Chiari II malformations? Acta Odontol Scand 2002;60:337-340.

12. Kjaer I. Prenatal traces of aberrant neurofacial growth. Acta Odontol Scand 1998;56:326-330.

13. Farley J, Dunleavy MJ. Myelodysplasia in primary care of the child with a chronic condition, third ed. St Louis: Mosby; 2000:658-674.

14. Haskins DR. Pediatric dental rehabilitation procedures in the OR. AORN J 1996;64:573-579.

15. Sussman G, Beezhold D. Allergic to latex rubber. Ann Intern Med 1995;122:43-46.

16. Sussman G, Beezhold D. Latex guideline, in standards, recommended practices, and guidelines. AORN J 2001:89-90.

17. Engibous PJ, Kittie PE, Jones HL, Vance BJ. Latex allergy in patients with spina bifida. Pediatric Dent 1993;15:364-366.

18. Nelson LP, Soporowski NJ, Shusterman S. Latex allergies in children with spina bifida: relevance for the pediatric dentist. Pediatric Dent 1994;16:18-22.

19. Estornell MF, Nieto GA, Mazon RA, Reig RC, Martinez VM, Dominguez HC, et al.. Latex allergy in children with myelomeningocele. Incidence and associated factors. Actas Urol Esp 1997;21:227-235.

20. Roy A, Epstein J, Onno E. Latex allergies in dentistry: recognition and recommendations. J Can Dent Assoc 1997;63:297-300.

Accepted October 21, 2009 